Akreditasi Risetdikti,

No 30/E/KPT/2019 (Sinta 4).

DOI: https://10.31294/jkom

\title{
Dominasi Korean Hallyu Dalam Konteks Strukturasi Di Industri Budaya
}

\author{
Safira Hasna
}

\author{
Ilmu Komunikasi Universitas Al Azhar Indonesia \\ e-mail: safirahasna2014@gmail.com
}

Diterima : 2021-01-02

Direvisi : 2021-02-20

Diterima : 2021-08-01

\begin{abstract}
The popularity of Korean dramas and songs triggers the dominance of Korean Hallyu internationally in various parts of the world. One of the factors which triggers this dominance is the Kpop Bangtan Sonyeodan boy band (BTS). BTS does not only create songs that are massive and standard but also has a meaning that makes them won a number of international awards. The objective of this paper is to analyze the dominance of Korean hallyu especially Korean boy band BTS as a pioneer of the Asian music industry internationally using structuration theory in the context of the cultural industry by using the literature review method, this is to describe a number of findings related to the cultural industry and structuration. As a result, BTS as an agent become an active participant who can reproduce the social system by referring to social actions that ultimately produce a social structure, BTS as an active agent can become a creative labour in the cultural industry by creating works that are not only profit-oriented but combines with the creativity which able to deliver messages through its music, as pioneer of Korean artists internationally.
\end{abstract}

Keywords: BTS, Korean Hallyu, Structuration, Cultural Industry

\section{PENDAHULUAN}

Saat ini, muncul Korean wave "hallyu" dalam bahasa korea yang mengacu pada meluasnya budaya Korea secara internasional, dimulai di Asia Timur pada 1990an dan berlanjut saat ini di Amerika Serikat, Amerika Latin, Timur Tengah, dan bagian dari Eropa lainnya (S. J. Lee, 2011). Mulai dari drama televisi Korea, film Korea, sampai musik Korea saat ini mendominasi industri di dunia.

Popularitas musik dan drama Korea memicu adanya Korean wave di dunia internasional. Jika dilihat dari sejarahnya, awal mula hallyu ini terjadi pada tahun 1997 ketika adanya drama TV Korea yang disiarkan di televisi Cina milik pemerintah, dan munculnya drama-drama lain. Sejak saat itu, muncul budaya populer Korea di negara-negara Asia dari tahun 2000-an, ketika penggemar barat tiba-tiba mulai menikmati K-pop, game digital, dan program televisi, termasuk drama dan reality shows. Sejak debut sukses beberapa artis Korea seperti Psy di Amerika Utara, beberapa grup idola, seperti Girls 'Generation, Twice, EXO, dan BTS, secara substansial meningkatkan aktivitas mereka di beberapa bagian dunia.

BTS (Bangtan Sonyeodan), boyband asal Korea Selatan hadir sebagai 'pelopor' Kpop grup di internasional. BTS adalah boyband Korea pertama yang tampil di American Music Awards pada November 2017, membawa pulang penghargaan di Billboard Music Awards 2017, dan boyband Korea pertama di 2018 Billboard Music Awards.

BTS atau dikenal sebagai Bangtan Boys merupakan grup Korea beranggotakan tujuh orang, membuat sejarah sebagai band $\mathrm{K}$ pop pertama yang memiliki debut album di No. 1 di chart Billboard Top 200 A.S. dengan albumnya "Love Yourself: Tear," dimana dalam minggu pertama memiliki jumlah yang setara dengan 135.000 keping penjualanan di Amerika Serikat (Chiu, 2018).

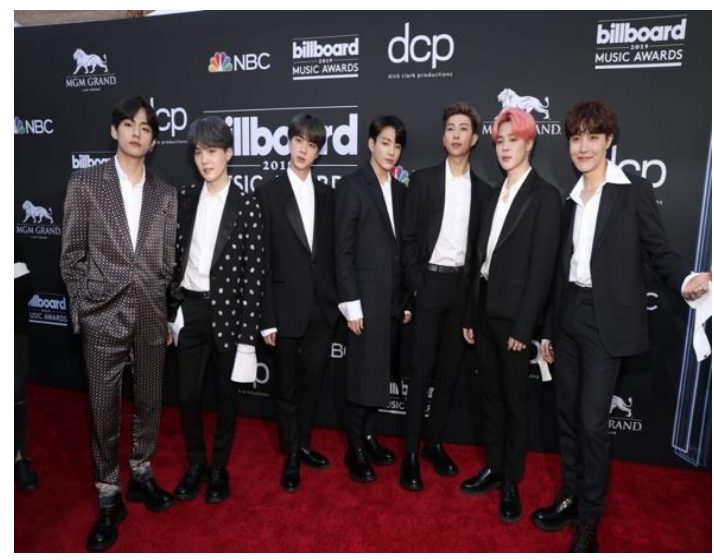

Sumber: Billboard.com Gambar 1. Boyband Korea BTS 
Industri musik kpop dapat dikategorikan sebagai industri budaya, dimana industri budaya mengacu pada produksi komoditas sebagai prinsip bentuk spesifik dari produksi budaya, dimana musik kpop diproduksi secara massif dan standard. Namun, di sisi lain BTS dapat menjadi suatu agensi dalam teori strukturasi yang membuat perubahan dalam industri musik dunia. Jika tadinya pemenang dalam ajang music awards seperti Billboard, American Music Award, di dominasi oleh musisi barat, BTS menjadi contoh sebagai wakil Asia dengan mengalahkan nominasi artis terkenal lainnya seperti Justin Bieber dan Taylor Swift. Bukan hanya itu, BTS sebagai artis dari perusahaan entertainment kecil di Korea dapat memberikan harapan bagi artis-artis dari perusahaan kecil lainnya untuk bisa sukses, baik di dalam negeri maupun luar negeri.

Penciptaan konten-konten yang berkaitan dengan BTS seperti lagu, mixtape (kumpulan lagu yang di buat sendiri untuk diberikan khusus kepada penggemar), koreografi mereka lakukan sendiri, dimana hal ini juga ada kaitannya dengan creative labour yang digagas oleh Hesmondalgh, yaitu adanya pencipataan makna yang memiliki implikasi kuat akan kebaruan, penemuan, inovasi, dan sesuatu yang 'fresh' (Hesmondhalgh \& Baker, 2011). Oleh karena itu, tujuan penulisan paper ini adalah untuk menganalisis adanya dominasi Korean hallyu khususnya boyband Korea BTS sebagai pelopor industri musik Asia di internasional dengan menggunakan teori strukturasi dalam konteks industri budaya dengan menggunakan metode literature review, yaitu memparkan sejumlah temuan terkait dengan industri budaya dan strukturasi.

Terdapat beberapa penelitian terdahulu terkait dengan Korean hallyu, industri budaya, dan strukturasi. Pada penelitian oleh Siriyuvasak dan Hyunjoon (2007) mengenai Asianizing K-pop: production, consumption, and identification patterns among Thai youth, penelitian mengeksplorasi fenomena Korean Hallyu di Thailand dan seberapa besar berdampak pada industri budaya di Asia Timur dengan menjelaskan mengenai keberhasilan budaya Korea (Kpop) yang mengambil alih Jpop menjadi 'asian pop' di wilayah Thailand. Penelitian juga menjelaskan bagaimana hubungan ekonomi politik yang ada dengan munculnya budaya Korea ini.
Penelitian kedua yang berjudul Drama Korea dan Budaya Popular oleh Velda Ardia (2014) meneliti tentang perkembangan budaya Korea di Indonesia dengan mendeskripsikan fenomena drama Korea yang menjadi budaya populer sehingga berdampak pada sektor pariwisata yang semakin meningkat dengan datangnya wisatawan mancanegara ke Korea, serta penggunaan produk-produk khas Korea. Penelitian menjelaskan adanya budaya pop Korea yang mendominasi hiburan global, dampak dari sektor pariwisata terlihat jelas dari meningkatnya jumlah wisatawan mancanegara yang datang, popoulernya elektronik, kuliner, pakaian dan lainnya yang otomatis memberikan citra yang baik di mata dunia melalui identitas yang disebarkan lewat budaya populernya.

Penelitian ketiga berjudul Крор Reception and Participatory Fan Culture in Austria oleh Yeon Sung (2013) menjelaskan mengenai popularitas Kpop dan penggemarnya yang telah berkembang di luar Asia dan bahkan menjadi signifikan di Eropa dalam beberapa tahun terakhir. Melalui wawancara mendalam dengan penyelenggara acara konser Kpop, sponsor, dan penggemar, penelitian melakukan studi etnografi dengan menunjukkan konsumsi Kpop berkembang pesat di Eropa. Munculnya festival dance Kpop di Vienna menjadi bukti adanya konsumsi Kpop, festival dance tersebut merupakan salah satu event terbesar yang pernah diselenggarakan di Vienna, dengan pengunjung berjumlah 400 orang, bahkan tiket berbayar pun habis terjual lewat event tersebut. Selama festival, menarik untuk melihat bagaimana orang-orang dari berbagai negara dapat terhubung dengan Kpop, yang berasal dari negara lain, dengan bahasa yang berbeda juga. Hal ini menumbuhkan tingkat konsumsi Kpop di negara Eropa serta menyebabkan adanya dominasi Korea di Eropa.

Ketiga penelitian menggunakan Korean Hallyu sebagai topik utama, namun perbedaannya, dalam penelitian ini dianalisis lebih lanjut bagaimana Korean Hallyu dapat mendominasi dunia internasional melalui teori strukturasi dalam perspektif industri budaya, dengan adanya boyband BTS sebagai agensi yang menyebabkan adanya struktur yang berubah dalam suatu sistem sosial. Penelitian ini juga menganalisis bagaimana BTS dan fansnya dapat menjadi creative labour yang mampu memproduksi budaya mereka untuk menjadi kreatif sehingga bukan hanya sekedar 
menyumbang kreativitas tetapi juga dapat menjadi nilai komersil.

Teori strukturasi yang dikembangkan oleh Anthony Giddens (1984) merupakan tanggapan klaim post-strukturalisme yang menyatakan bahwa struktur ditentukan oleh manusia sendiri dengan dasar kesukarelaan, yang menunjukkan bahwa manusia dengan bebas menciptakan lingkungan hidup mereka. Dasar dari teori strukturasi adalah adanya keterlibatan hubungan antara individu dengan kekuatan sosial yang ada. Dalam teori strukturasi Giddens, ia mencoba menyeimbangkan peran oleh para aktor dengan tatanan sosial yang dimilikinya. Dalam teorinya, Giddens mengatakan bahwa tindakan dan pengetahuan individu tidak dibatasi, mereka dapat menciptakan kembali struktur sosial dan menghasilkan perubahan sosial (Lamsal, 2012).

\section{Strukturasi}

Strukturasi menekankan pada analisis struktur dan agen. Strukturasi terjadi jika agensi menggunakan berbagai aturan dan sumber daya (resources) sistem mereka dengan mereproduksi atau mengubah prinsip-prinsip struktural yang mengatur kegiatan mereka sejak awal (Whittington, 2015). Menurut teori strukturasi, agen dapat menjadi partisipan aktif yang dapat mereproduksi sistem sosial dengan merujuk pada tindakan sosial melalui pelacakan memori (memory traces), yang pada akhirnya menghasilkan lagi struktur sosial.

Untuk mempelajari strukturasi, Giddens menggunakan gagasan duality structure, dimana sifat-sifat struktural dari sistem sosial adalah medium dan hasil dari praktik-praktik yang telah dilakukan. Struktur hadir secara internal, yaitu di dalam agen sebagai memory traces seperti yang dipakai dalam praktik sosial, dan eksternal sebagai manifestasi tindakan sosial (Giddens, 1984).

Manusia berperilaku berdasarkan yang diketahui tentang tindakannya dan mengapa ia melakukan hal tersebut (knowledgeability), dimana menurut Giddens (1984) hal itu terbentuk oleh: dominasi, signifikansi, dan legitimasi. Dominasi berfokus pada produksi (dan pelaksanaan) kekuatan, yang berasal dari kontrol sumber daya. Dalam konteks Giddens berbeda dengan Marx, yang menyebutkan adanya hubungan antara 'alat-alat produksi' dalam masyarakat kapitalis, sedangkan dominasi disini adalah untuk memahami hubungan kekuasaan sebagai suatu bentuk interaksi antara aktor dan struktur. Dalam interaksi ini, sumberdaya dapat diilustrasikan sebagai bentuk hubungan antara atasan dan bawahannya. Sumberdaya juga dapat digunakaan dalam bentuk properti atau alokasi kekayaan. Signifikansi, yaitu mengacu pada makna melalui bahasa yang terorganisir. Giddens memperluas peran aktor dalam sistem sosial untuk dapat menafsirkan dan memanipulasi bahasa terstruktur dengan makna interpretif. Sedangkan legitimasi menghasilkan tatanan moral melalui naturalisasi norma, nilai, dan standar masyarakat. Ketika agen individu berinteraksi, mereka menunjukkan makna secara sadar, atau tidak sadar (Giddens menyebutnya sebagai sanksi) dari perilaku mereka. Berinteraksi dengan cara ini membentuk norma sosial saat ini dan ditimbang terhadap aturan moral struktur. Karena itu, apakah suatu tindakan dianggap sah atau tidak dalam tatanan sosial terstruktur oleh dimensi legitimasi ini.

Jika membicarakan tentang strukturasi, tidak akan dapat terpisahkan dengan konsep agent-agency, dimana agensi dapat diartikan sebagai tindakan dasar manusia dan segala kegiatan yang dihasilkan sebagai dua kemampuan yang menentukan sistem sosial. Agency dapat memberdayakan reflexive monitoring yaitu kemampuan untuk memonitor tindakan, setting, dan konteks tindakan. Melalui tindakan, agen memproduksi dan mereproduksi suatu struktur. Akibatnya, struktur ini dapat berubah karena ada orang-orang yang ingin menjadi agency.

Terdapat dimensi internal agen yang dapat mempengaruhi struktur menjadi suatu sistem sosial, pertama unconscious motives, yaitu adanya motivasi bawah sadar dari perilaku manusia melalui reflexive monitoring, kedua practical consciousness yaitu adanya perilaku yang dilakukan secara berulang-ulang, dan discursive consciousness yaitu justifikasi hal yang telah dilakukan. Ketiganya jika dilakukan terus lama kelamaan akan menjadi suatu sistem sosial (Giddens, 1984).

\section{Industri Budaya}

Industri budaya pertama kali dikenalkan oleh pemikiran Theodor Adorno dan Marx Horkheimer pada abad 19, tahun 1940-an oleh Theodor W. Adorno, anggota Frankfurt School yang berpengaruh, yang terdiri dari para pemikir ilmiah dari Nazi Jerman. Adorno dan 
Horkheimer menggunakan dua contoh dalam mendeskripsikan industri budaya.

Dalam contoh pertama, 'industri budaya' mengacu pada produksi komoditas sebagai prinsip bentuk spesifik dari produksi budaya. Budaya berbentuk komoditas berbeda dengan gagasan budaya borjuis sebagai sesuatu yang melambangkan artl'art pour l'art ', sebagaimana dinyatakan oleh beberapa penulis dan seniman pada abad kesembilan belas. Industri budaya menunjukkan cabang produksi tertentu, yang terdiri dari studio film, fasilitas rekaman, pabrik $\mathrm{CD}$, mesin cetak yang memproduksi kertas secara cepat dan dengan jumlah yang banyak (atau dalam gambar yang muncul dalam film yang tak terhitung jumlahnya), stasiun radio dan TV dengan liputan global, dan pertunjukan panggung. Industri budaya dapat diartikan sebagai pabrik untuk barang budaya. Pada akhirnya, menurut Adorno, budaya diproduksi secara massif dan standard

bukan berasal dari ekspresi kultural rakyat tetapi produk dari industri semata menyatukan yang lama dengan yang familiar, ke dalam kualitas produk industri (Steinert, 2003).

Pada akhirnya, lahir istilah industri budaya yang mengacu pada industri yang menggabungkan penciptaan, produksi, dan komersialisasi konten kreatif baik yang tangible maupun intangible dan bersifat budaya. Konten biasanya dilindungi oleh hak cipta dan berbentuk barang atau layanan. Industri budaya pada umumnya meliputi percetakan, penerbitan dan multimedia, produksi audio-visual, fotografi dan sinematografi serta kerajinan dan desain (Witkin, 2003).

\section{Creative Labour}

Untuk memahami industri budaya lebih lanjut, David Hesmondhalgh (2011) melakukan identifikasi dengan melakukan berbagai pendekatan, khususnya pada proses produksi budaya yang fokus pada pekerjanya yang kreatif (creative labour). Saat ini dalam proses produksi budaya akan membuat peluang besar bagi mereka untuk menjadi kreatif, dan tentu saja ke-kreatifan mereka bukan sekedar kreativitas dalam seni dan estetika, tetapi lebih kepada institusi yang lebih menonjol (baik film, televisi, bisnis musik) yang dikenal seagai media, yang pada akhirnya digunakan untuk perusahaan komersial.
Sebelum masuk ke dalam creative labour, berikut beberapa tahap produksi budaya:

Tabel 1. Division of Labour in Production

\begin{tabular}{|c|c|c|c|c|c|}
\hline Stage & Phase & Object & $\begin{array}{l}\text { Publis } \\
\text { hing }\end{array}$ & $\begin{array}{l}\text { Recordi } \\
n g\end{array}$ & Filming \\
\hline \multirow[t]{2}{*}{$\begin{array}{l}\text { Creativ } \\
e\end{array}$} & \multirow{2}{*}{$\begin{array}{l}\text { Creatio } \\
n: \\
\text { producti } \\
\text { on to } \\
\text { original }\end{array}$} & $\begin{array}{l}\text { Prepara } \\
\text { tion of } \\
\text { original } \\
\text { (plan) }\end{array}$ & Idea & $\begin{array}{l}\text { Compos } \\
\text { ition } \\
\text { (score) }\end{array}$ & $\begin{array}{l}\text { Writing } \\
\text { (screen } \\
\text { play) }\end{array}$ \\
\hline & & $\begin{array}{l}\text { Perform } \\
\text { ance of } \\
\text { original } \\
\text { (perfor } \\
\text { mance) }\end{array}$ & $\begin{array}{l}\text { Redra } \\
\text { fting } \\
\text { and } \\
\text { editin } \\
g \\
\text { (type } \\
\text { script } \\
\text { ) }\end{array}$ & $\begin{array}{l}\text { Rehears } \\
\text { al \& } \\
\text { perform } \\
\text { ance } \\
\text { (perfor } \\
\text { mance) }\end{array}$ & $\begin{array}{l}\text { Rehears } \\
\text { al \& } \\
\text { perform } \\
\text { ance } \\
\text { (perfor } \\
\text { mance) }\end{array}$ \\
\hline \multirow[t]{4}{*}{$\begin{array}{l}\text { Reprod } \\
\text { uction }\end{array}$} & \multirow[t]{2}{*}{$\begin{array}{l}\text { Transcri } \\
\text { ption: } \\
\text { producti } \\
\text { on of } \\
\text { master }\end{array}$} & $\begin{array}{l}\text { Transcri } \\
\text { ption of } \\
\text { orginina } \\
l \\
\text { (transcr } \\
\text { ipt) }\end{array}$ & $\begin{array}{l}\text { Type } \\
\text { settin } \\
g \\
\text { (proof } \\
\text { s) }\end{array}$ & $\begin{array}{l}\text { Recordi } \\
\text { ng } \\
\text { studio } \\
\text { (recordi } \\
\text { ng) }\end{array}$ & $\begin{array}{l}\text { Film } \\
\text { studio } \\
\text { set } \\
\text { (filming } \\
\text { ) }\end{array}$ \\
\hline & & $\begin{array}{l}\text { Editing } \\
\& \\
\text { masteri } \\
n g \quad \text { of } \\
\text { transcri } \\
\text { pt } \\
\text { (master) }\end{array}$ & $\begin{array}{l}\text { Plate } \\
\text { makin } \\
g \\
\text { (plate } \\
\text { ) }\end{array}$ & $\begin{array}{l}\text { Post- } \\
\text { producti } \\
\text { on } \\
\text { editing } \\
\text { etc } \\
\text { (master) }\end{array}$ & $\begin{array}{l}\text { Post- } \\
\text { producti } \\
\text { on } \\
\text { editing } \\
\text { etc } \\
\text { (master) }\end{array}$ \\
\hline & $\begin{array}{l}\text { Duplicat } \\
\text { ion: } \\
\text { producti } \\
\text { on of } \\
\text { copies }\end{array}$ & $\begin{array}{l}\text { Copying } \\
\text { from } \\
\text { master } \\
\text { (copies) }\end{array}$ & $\begin{array}{l}\text { Printi } \\
\text { ng } \\
\text { (page } \\
\text { s }\end{array}$ & $\begin{array}{l}\text { Pressin } \\
g \quad(\text { disc }, \\
\text { tape })\end{array}$ & $\begin{array}{l}\text { Printing } \\
\text { (copy) }\end{array}$ \\
\hline & & $\begin{array}{l}\text { Packagi } \\
\text { ng of } \\
\text { copies } \\
\text { (commo } \\
\text { dities) }\end{array}$ & $\begin{array}{l}\text { Bindi } \\
n g \quad \& \\
\text { coveri } \\
\text { ng } \\
\text { (book } \\
\text { ) }\end{array}$ & $\begin{array}{l}\text { Packagi } \\
\text { ng } \\
\text { labeling } \\
\text { (recordi } \\
\text { ngs) }\end{array}$ & $\begin{array}{l}\text { Packagi } \\
\text { ng as } \\
\text { film } \\
\text { print or } \\
\text { video } \\
\text { cassette }\end{array}$ \\
\hline
\end{tabular}

\section{Sumber: (Ryan, 1991)}

Poin pertama dan paling penting untuk diperhatikan adalah bahwa produksi budaya dibagi menjadi dua tahap berbeda; kreasi dan reproduksi. Karya artistik dan kreatif mencakup konsepsi dan pelaksanaan, hasil akhirnya adalah original, ini harus dijadikan komoditas yang melibatkan produksi ulang secara kuantitas. Tahap reproduksi memiliki dua tahap; transkripsi di mana aslinya diubah menjadi lebih baik lagi, dari fase duplikasi, salinan - komoditas yang tepat - difinalisasikan, kemudian dikemas dan didistribusikan ke outlet ritel (Ryan, 1991).

Teori Adorno dan Horkheimer mengenai industri budaya jauh dari kata 'industri kreatif', namun kenyataannya saat ini teknologi membuat seseorang bebas untuk 
berkarya secara aktif dan kreatif, bahkan perusahaan dapat merangkul pekerja kreatif untuk dapat memberikannya pengalaman, identitas, kepuasan pribadi yang intens, pengorganisasian diri yang refleksif, serta kesenangan afektif, namun sering kali bersifat eksploitatif (D. Lee, 2013).

\section{METODOLOGI PENELITIAN}

Dalam menulis paper ini, penulis menggunakan studi kepustakaan, dimana metode ini memberikan kemungkinan untuk memiliki visi yang jelas ini terkait dengan topik tertentu dan untuk input yang tepat (Tikito \& Soussi, 2019). Studi kepustakaan adalah ringkasan objektif, menyeluruh dan analisis kritis dari penelitian yang tersedia relevan dan literatur non-penelitian tentang topik yang sedang dipelajari (Hart, 1998 dalam (Cronin, Ryan, \& Coughlan, 2014)). Tujuannya adalah menjadikan pembaca mengetahui suatu topik berdasarkan tujuan dari penelitian, serta pembenaran untuk penelitian di masa depan tentang topik yang terkait. Suatu studi kepustakaan yang baik yang baik adalah mengumpulkan informasi tentang objek tertentu dari banyak sumber, ditulis dengan baik dan ditambah dengan pendapat penulis sendiri.

Parahoo (2006) mengemukakan bahwa literature review harus merinci kerangka teori / konsep yang dipilih dan mengevaluasi temuan yang bersangkutan dengan topik penelitian. Agar pembaca dapat menilai kahandalan dan validitas ulasan, penulis perlu menyajikan kriteria seperti: merumuskan pertanyaan penelitian, menetapkan kriteria dan pengecualian yang harus direview dalam tulisan, memilih dan mengakses literatur, dan menganalisis, mensintesis dan menyebarluaskan temuan (Cronin et al., 2014).

Oleh karena itu, dalam penelitian ini penulis merinci konsep yang berkaitan dengan topik penelitian yaitu strukturasi, industri budaya, dan creative labour, setelah itu penulis merumuskan pertanyaan penelitian yaitu "bagaimana dominasi Korean Hallyu di ranah global dalam konteks strukturasi di industri budaya?" Dengan meninjau konsep-konsep yang terkait di dalamnya (dari tinjauan literatur yang sudah ada, baik dalam jurnal maupun buku), kemudian penulis mensintesis temuan yang di dapat.

\section{HASIL DAN PEMBAHASAN}

Dari latar belakang masalah yang ada, penulis menyadari adanya keterkaitan antara Korean hallyu dengan teori strukturasi serta creative labour dalam konteks industri budaya. BTS, boyband Korea menjadi agensi yang mampu memberikan dampak serta perubahan dalam industri musik dunia. Jika dulu yang mampu memenangkan ajang musik internasional bergengsi seperti Billboard dan AMA adalah barat, maka saat ini Asia memiliki peluang untuk menang. Setelah BTS, industri musik barat banyak melakukan kolaborasi dengan banyak artis Korea, serta banyaknya artis Korea yang diundang di acara televisi Amerika.

Strukturasi terjadi jika agensi menggunakan berbagai aturan dan sumber daya (resources) sistem mereka dengan mereproduksi atau mengubah prinsip-prinsip struktural yang mengatur kegiatan mereka sejak awal (Whittington, 2015). Menurut teori strukturasi, agen dapat menjadi partisipan aktif yang dapat mereproduksi sistem sosial dengan merujuk pada tindakan sosial yang pada akhirnya menghasilkan lagi suatu struktur sosial.

Dalam hal ini, BTS menjadi agen yang menggunakan berbagai aturan dan sumber daya untuk menghasilkan lagi suatu struktur sosial. BTS memproduksi sebuah lagu dengan lirik serta koreografi yang mereka ciptakan sendiri. Jika biasanya artis Korea menggunakan produser serta koreografer terkenal, BTS bekerja sama dengan sesama anggotanya untuk menciptakan karya yang dapat menginspirasi siapapun pendengarnya, bahkan nama mereka sendiri BTS memiliki arti untuk melindungi serta membantu masalah tentang kekhawatiran orang-orang, khususnya remaja. Nama fanclubnya juga dibuat memiliki makna serupa yaitu ARMY (Adorable Representative M.C for Youth).

"The name was chosen to represent the main goal of the group: to protect and to talk about the problems and worries of people in their teens and twenties." (Wickman, 2018).

Melalui lagu debutnya yang berjudul "No More Dream", BTS mendiskusikan tentang bagaimana masalah remaja yang tidak peduli dengan mimpi dan masa depannya, lalu album selanjutnya "School Trilogy" meneruskan tema yang telah ada serta mengkritik keadaan sosial yang ada saat ini. Dari awal, musik yang diciptakan BTS bukan 
sekedar musik yang ingin menjual, tetapi juga telah berfokus pada keadaan anak muda serta kritik sosial. Album terbarunya pada 2018 Love Yourself, juga memberikan makna kepada para pendengarnya untuk lebih mencintai dirinya sendiri sebagai solusi atas permasalahan mereka. Bukan hanya itu, BTS yang lahir dari entertainment company yang relatif kecil juga menjadi sorotan dunia, karena biasanya artis Korea yang berhasil tekenal adalah mereka yang berada di perusahaan besar seperti SM, YG, atau JYP Entertainment.

Bukan sekedar memproduksi lagu, lewat karyanya BTS juga bekerja sama dengan UNICEF untuk menggelar kampanye melawan kekerasan terhadap anak-anak dan remaja di seluruh dunia, dengan harapan membuat dunia menjadi tempat yang lebih baik melalui musik, kampanye yang bekerja sama dengan UNICEF ini dapat diakses melalui website. UNICEF juga memilih BTS untuk berpidato di sidang PBB 2018 di New York dengan harapan dapat menginspirasi generasi muda di belahan dunia.

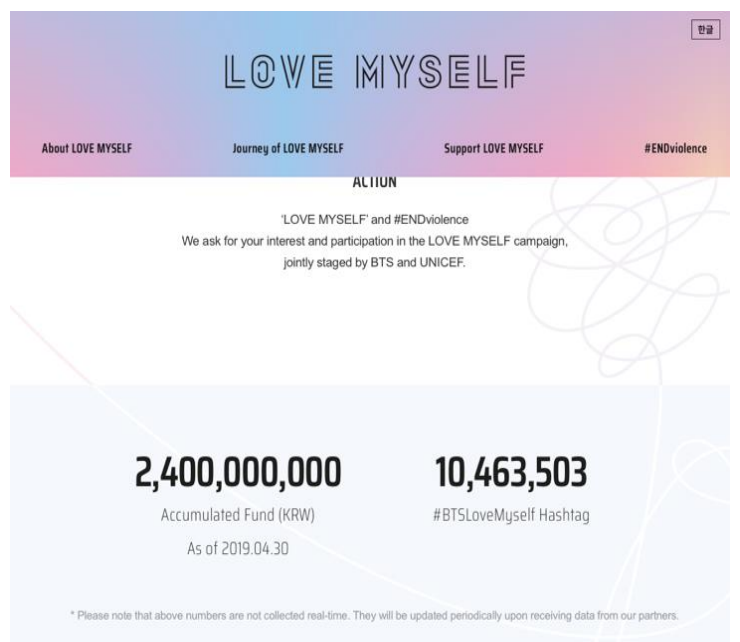

Sumber:https://www.love-myself.org/eng/home/. Gambar 2. Kampanye "Love Myself” oleh BTS dan UNICEF

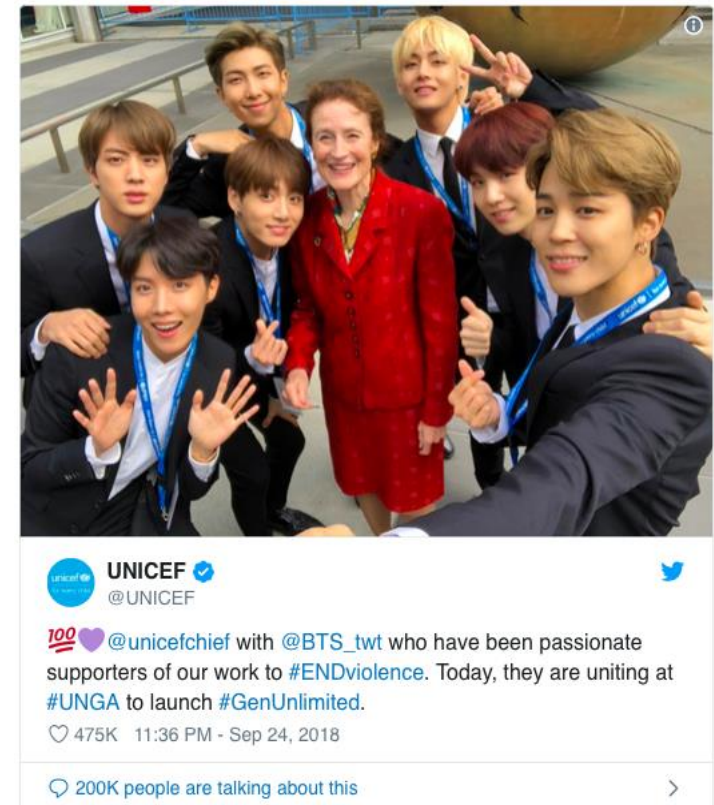

Sumber: twitter.com/UNICEF

Gambar 3. Update Twitter UNICEF saat BTS menghadiri Sidang PBB 2018

\section{KESIMPULAN}

Dari pembahasan mengenai Korean Hallyu yang mendominasi secara internasional, dapat disimpulkan bahwa ada agen perubahan yang membawa dominasi tersebut, yaitu boyband asal Korea BTS. BTS sebagai agen dapat menjadi partisipan aktif yang dapat mereproduksi sistem sosial dengan merujuk pada tindakan sosial yang pada akhirnya menghasilkan lagi suatu struktur sosial, sebagai pelopor artis Korea di internasional dengan memproduksi lagu serta koreografi sendiri, selalu menghasilkan lagu yang menghasilkan makna yang mendalam sehingga dapat menjadi inspirasi bagi para pendengarnya, khususnya target musik mereka yaitu generasi muda. Kpop juga bukan lagi hanya dipandang sebagai performer semata tetapi juga mampu membawa pesan yang bermakna. BTS membuka peluang bagi artis Asia lainnya khususnya Korea untuk berkolaborasi dengan artis barat, tampil dengan impresif di ajang musik internasional, serta mendapatkan penghargaan dan masuk ke chart Billboard. BTS sebagai agen aktif dapat menjadi creative labour di dalam industri budaya dengan penciptaan karya yang bukan hanya berorientasi pada keuntungan semata, tetapi menggabungkan penciptaan ide dengan kreatifitas yang mampu memberikan pesan melalui musiknya. Peranan fans sebagai free labour juga berpengaruh besar dalam kesuksesan BTS sebagai pembawa struktur 
sosial baru, dengan mereka mendukung segala aktifitas lewat like, comment, subscribe, voting sehingga BTS sebagai agen boyband asal Korea mendapatkan citra yang positif di masyarakat luas.

\section{REFERENSI}

Chiu, A. (2018). South Korean boy band BTS makes history: First K-pop group to top U.S. Billboard 200 chart. Retrieved June 10, 2019, from https://www.washingtonpost.com/news/m orning-mix/wp/2018/05/29/south-koreanboy-band-bts-makes-history-as-first-kpop-group-tops-u-s-billboard-200chart/?noredirect=on\&utm_term $=.53 \mathrm{ad} 41$ 162195

Cronin, P., Ryan, F., \& Coughlan, M. (2014). Undertaking a literature review: a step-bystep approach. British Journal of Nursing, $17(1)$ $38-43$. https://doi.org/10.12968/bjon.2008.17.1.2 8059

Giddens, A. (1984). The Constitution of the Society. Transactions of the Geological Society of Glasgow (Vol. 13). Berkeley: University of California Press. https://doi.org/10.1144/transglas.13.1.118

Hesmondhalgh, D., \& Baker, S. (2011). Creative Labour. New York: Routledge.

Lamsal, M. (2012). The Structuration Approach of Anthony Giddens. Himalayan Journal of Sociology and Anthropology, 5, 111122.

https://doi.org/10.3126/hjsa.v5i0.7043

Lee, D. (2013). Creative labour in the cultural industries. Sociopedia.Isa, 1-13. https://doi.org/10.1177/205684601181

Lee, S. J. (2011). The Korean Wave: The Seoul of Asia. The Elon Journal of

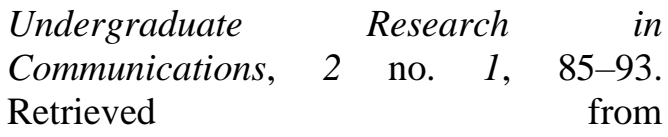

https://www.elon.edu/docs/e-

web/academics/communications/research/ vol2no1/09suejin.pdf

Ryan, B. (1991). Making Capital from Culture: The Corporate Form of Capitalist Cultural Production. Berlin: Walter de Gruyter \& Co.

Steinert, H. (2003). Culture Industry. New Jersey: Wiley.

Tikito, I., \& Soussi, N. (2019). Meta-analysis of Systematic Literature Review Methods. I.J. Modern Education and Computer Science, 2(February), 17-25. https://doi.org/10.5815/ijmecs.2019.02.03

Whittington, R. (2015). Giddens, structuration theory and strategy as practice. Cambridge Handbook of Strategy as Practice, Second Edition, (January), 145164.

https://doi.org/10.1017/CCO97811396810 32.009

Wickman, G. (2018). Love Yourself: The Message Behind BTS's Record Breaking Album Series. Retrieved June 11, 2019, from https://medium.com/bangtanjournal/love-yourself-the-message-behindbtss-record-breaking-album-series$229119 \mathrm{e} 81902$

Witkin, R. W. (2003). Adorno on Popular Culture. New York: Routledge.

\section{PROFIL PENULIS}

Safira Hasna, seorang Dosen Ilmu Komunikasi Fakultas Ilmu Sosial dan Ilmu Politik, Universitas Al Azhar Indonesia. 